\title{
Kinerja Lalu-lintas Simpang di Kalen-Majenang Akibat Pembangunan Saluran Irigasi Waduk Kalen di Kecamatan Kedungpring Kabupaten Lamongan
}

\author{
Intersection Traffic Performance at Kalen-Majenang Due to the \\ Construction of Kalen Reservoir Irrigation Channel in Kedungpring \\ Distric Lamongan Regency
}

\author{
R. Endro Wibisono ${ }^{1, a)} \&$ M. Shofwan Donny Cahyono ${ }^{2, b)}$ \\ ${ }^{1)}$ Program Studi Teknik Sipil, Fakultas Teknik, Universitas Narotama Surabaya \\ ${ }^{2)}$ Program Studi Teknik Sipil, Fakultas Teknik, Universitas Widya Kartika Surabaya
}

Koresponden $\quad:{ }^{a}$ r.endro.wibisono@narotama.ac.id \& ${ }^{b}$ shofwandonny@widyakartika.ac.id

\begin{abstract}
ABSTRAK
Di Kecamatan Kedungpring, Kabupaten Lamongan terdapat Waduk Kalen didekat Jalan Raya Babat. Saat ini sedang dilaksanakan pembangunan Saluran Primer Prijetan, dan Saluran Sekunder Kandangrejo di sepanjang Jalan Balongsari (Kalen - Pasar Kedungpring), serta pembangunan Saluran Sekunder Kandangrejo di sepanjang sisi Jalan Olahraga (ruas Jalan Kedungpring - Jalan Majenang). Adanya operasional pembangunan saluran di sisi jalan tersebut akan memberi pengaruh langsung terhadap kinerja lalu-lintas disekitar Simpang Raya Babat, Simpang Pasar Kedungpring, dan Simpang Majenang. Karena kendaraan yang melintas sudah tentu didominasi oleh kendaraan berat/ barang. Pengerjaan pembangunan saluran irigasi sekunder disepanjang sisi Jalan Kalen - Jalan Majenang dioperasikan tahun 2019. Hasil perhitungan kinerja lalu-lintas Simpang A pasca konstruksi (2019) angka Derajat Kejenuhan (DK) = 0,626, dengan Tingkat Pelayanan (TP) C (cukup). Simpang B pasca konstruksi (2019) angka Derajat Kejenuhan (DK) $=0,646$, denganTingkat Pelayanan (TP) C (cukup). Simpang C pasca konstruksi (2019) angka Derajat Kejenuhan $(\mathrm{DK})=0,390$, dengan Tingkat Pelayanan (TP) B (baik) dimana menurut MKJI arus stabil pergerakan dibatasi, tingginya volume lalu-lintas.
\end{abstract}

Kata Kunci: manajemen aset infrastruktur, jalan, operasional, kinerja lalu-lintas, derajat kejenuhan, tundaan.

\section{PENDAHULUAN}

Infrastruktur jalan merupakan infrastruktur vital bagi suatu wilayah. Jalan harus dikelola dengan baik sesuai prinsip Manajemen Aset Infrastruktur (Suprayitno \&Soemitro, 2018). Terkait Manajemen Aset Infrastruktur, dalam kenyataannya operasional jalan bisa terganggu oleh pembangunan saluran irigasi. Dampak mengenai hal ini perlu untuk dikaji lebih lanjut.

Di Kecamatan Kedungpring, Kabupaten Lamongan terdapat Waduk Kalen didekat Jalan Raya Babat. Saat ini sedang dilaksanakan pembangunan Saluran Primer Prijetan, dan Saluran Sekunder Kandangrejo di sepanjang Jalan Balongsari (Kalen - Pasar Kedungpring), serta pembangunan Saluran Sekunder Kandangrejo di sepanjang sisi Jalan Olahraga (Simpang Jalan Kedungpring - Jalan Majenang). Adanya operasional pembangunan saluran di sisi jalan tersebut akan memberi pengaruh langsung terhadap kinerja lalu-lintas disekitar Simpang Raya Babat, Simpang Kedungpring, dan Simpang Majenang, karena kendaraan yang melintas 
sudah tentu didominasi oleh kendaraan berat/barang. Pengerjaan pembangunan saluran irigasi sekunder disepanjang sisi Jalan Kalen - Jalan Majenang dipercepat agar bisa dioperasikan tahun 2019.

Dampak lalu-lintas akibat pekerjaan pembangunan saluran harus diteliti. Pertanyaan untuk penelitian ini adalah: bagaimana kinerja lalu lintas di simpang di sekitar lokasi studi (Kedungpring Lamongan) tahun 2018 (saat saluran sekunder masih dalam pengerjaan)?, bagaimana prediksi kinerja lalu lintas di simpang di lokasi studi (Kedungpring Lamongan) tahun 2019 (saat saluran sekunder mulai beroperasi)?

\section{METODA PENELITIAN}

Tahapan dalam penelitian ini dimulai dengan mengetahui tujuan penelitian dan pemahaman literatur yang akan digunakan sebagai panduan dan referensi dalam penelitian dan menentukan data apa yang dibutuhkan.

Analisa lalu-lintas dilakukan untuk tahun 2018 saat pembangunan saluran dan untuk tahun 2019 saat selesai pembangunan saluran. Survei dilakukan tahun 2017 saat pembangunan saluran untuk mencari data primer berupa pencacahan jumlah kendaraan yang keluar masuk Simpang Jalan Raya Babat - Jalan Kalen, Simpang Kalen-Kedungpring, dan Simpang Kedungpring-Majenang pada jam puncak pagi jam 06:00-08:00 tanggal 12-14 Desember. Oleh karena itu dari hasil perhitungan tahun 2017 ada prediksi Derajat Kejenuhan (DK), Tundaan Rata-rata (TR), dan Tingkat Pelayanan (TP) untuk setiap simpang tahun 2018 dan 2019. Prediksi DK, TR, dan TP dilakukan dengan menggunakan angka pertumbuhan jumlah kendaraan 5 tahun terakhir di Kabupaten Lamongan.

DK adalah rasio arus lalu-lintas terhadap kapasitas, TR adalah tundaan lalu-lintas simpang rata-rata, dan TP adalah ukuran kwalitatif yang menerangkan kondisi operasional dalam arus lalu-lintas (MKJI, 1997).

- Rumus DK

$\mathrm{DK}=\mathrm{Q}_{\mathrm{tot}}$

Keterangan :

$\begin{array}{ll}\text { DK } & \text { : Derajat Kejenuhan } \\ \mathrm{Q}_{\text {tot }} & : \text { Arus Total (smp/jam) } \\ \mathrm{C} & : \text { Kapasitas (smp/jam) }\end{array}$

- $\quad$ Rumus TR

$\mathrm{TR}=\mathrm{DG}+\mathrm{DT} 1$

Keterangan :

TR : Tundaan Rata-rata (det/smp)

DG : Tundaan Geometrik Simpang (det/smp)

DT1 : Tundaan Lalu-lintas Simpang (det/smp)

- Rumus DG

$\mathrm{DG}=(1-\mathrm{DK}) \times(\mathrm{PT} \times 6+(1-\mathrm{PT}) \times 3)+\mathrm{DK} \times 4(\mathrm{det} / \mathrm{smp})$

Keterangan :

DG : Tundaan Geometrik Simpang

DK : Derajat Kejenuhan

PT : Rasio Belok Total. 
- Grafik DT1

Tundaan lalu-lintas simpang adalah tundaan lalu-lintas, rata-rata untuk semua kendaraan bermotor yang masuk simpang. DT1 ditentukan dari kurva empiris antara DT1 dan DK (MKJI,1997). Untuk lebih jelasnya disajikan pada Gambar 1.

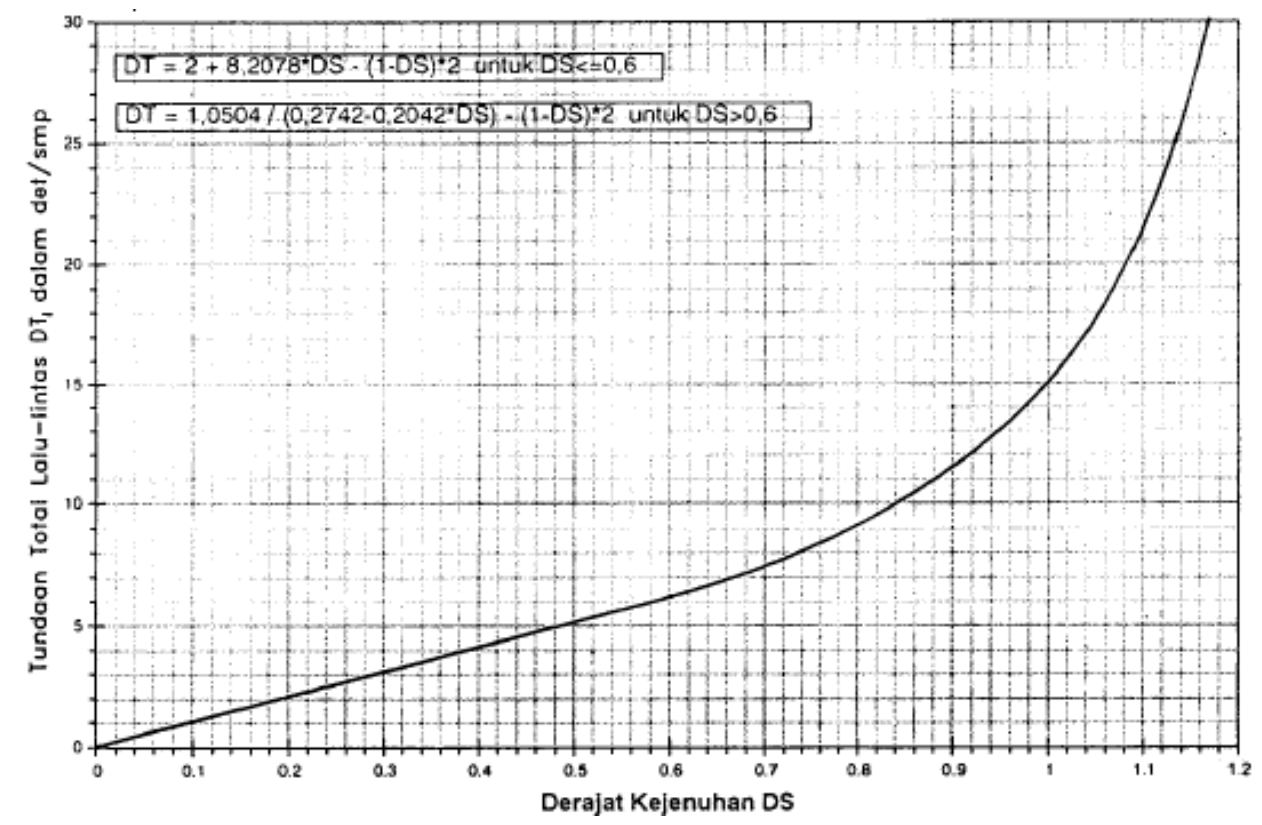

Gambar 1. Tundaan Lalu-lintas Simpang (DT1)

Sumber : MKJI 1997, Halaman 3-40

- Tabel TP

Tabel 1. Kriteria Tingkat Pelayanan Jalan

\begin{tabular}{ccl}
\hline DK & TP & \multicolumn{1}{c}{ Ciri Lalulintas } \\
\hline $0-0,19$ & A & Arus bebas, volume rendah, kecepatan tinggi, kepadatan rendah. \\
$0,20-0,44$ & B & Arus stabil dan mulai ada pembatasan kecepatan. \\
$0,45-0,69$ & C & Arus stabil, pergerakan dibatasi, tingginya volume lalu-lintas. \\
$0,7-0,84$ & D & Arus mendekati tidak stabil, kecepatan mulai terganggu kondisi jalan \\
$0,85-1$ & E & Terjadi kemacetan lalu-lintas. \\
$>1$ & F & Sering terjadi kemacetan dan antrian panjang. \\
\hline \multicolumn{3}{c}{ Sumber : Manual Kapasitas Jalan Indonesia 1997, Halaman 7-70 }
\end{tabular}

Nilai emp (Ekivalen Mobil Penumpang) yang dipakai adalah menurut MKJI 1997. Berdasarkan jenis kendaraan, nilai emp disajikan pada Tabel 2 berikut ini.

Tabel 2. Nilai emp (Ekivalen Mobil Penumpang) Berdasarkan Jenis Kendaraan

\begin{tabular}{ccc}
\hline No & Jenis Kendaraan & Nilai emp \\
\hline 1 & Bus/Truk Besar & 1,3 \\
2 & Bus/Truk Kecil & 1,0 \\
3 & Sepeda Motor & 0,5 \\
\hline & Sumber : Manual Kapasitas Jalan Indonesia 1997, Halaman 3-26
\end{tabular}




\section{PENGUMPULAN DATA}

Di Kecamatan Kedungpring, saluran irigasi yang dibangun meliputi: Saluran Primer Prijetan, dan Saluran Sekunder Kandangrejo. Saluran Primer Prijetan berada di sepanjang samping ruas Jalan Kalen, kemudian berbelok ke kiri di titik Jalan Kalen-Bendalem dan disepanjang samping Jalan Bendalem. Sedangkan Saluran Sekunder Kandangrejo berada di sepanjang samping Jalan Kalen - Jalan Kedungpring, dan setelah itu Jalan Majenang berbelok ke kiri di titik Jalan Olahraga. Jadi terdapat tiga simpang yang mengalami dampak pembangunan saluran, ketiga simpang adalah sebagai berikut:

- Simpang A (Jl. Raya Babat - Jl. Kalen)

- Simpang B (Jl. Kalen - Jl. Kedungpring)

- Simpang C (Jl Kedungpring - Jl. Majenang)

Titik simpang dan posisi saluran sekunder selengkapnya dapat dilihat pada Peta Lokasi pada Gambar 2 berikut ini.

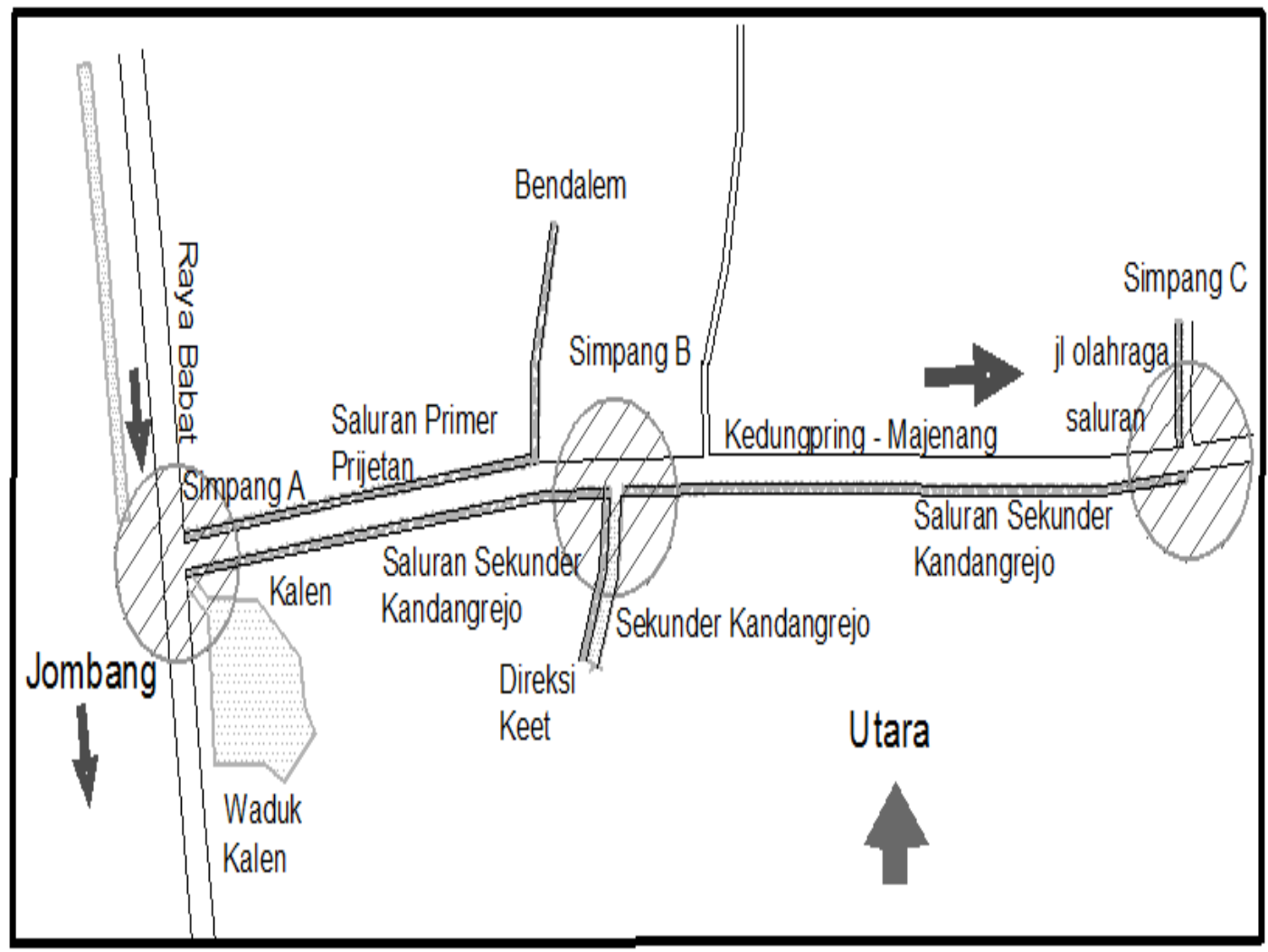

Gambar 2. Peta Lokasi Pengamatan

Dianggap perlu dilakukan pengamatan pada 3 simpang tersebut karena sering dilalui kendaraan berat mengingat letaknya yang berdampingan langsung dengan saluran. Survei lalu-lintas dilakukan pada 3 simpang. Data survei lalu-lintas digunakan untuk menghitung kinerja lalu-lintas pada Simpang A yang merupakan Jalan Propinsi di arah Utara-Selatan Jalan Raya Babat, pada Simpang B yang merupakan area Pasar Kedungpring arah Barat-Timur, pada Simpang C yang merupakan area Pasar Majenang arah Barat-Timur. Berdasarkan hasil survei tahun 2017 didapatkan data lalu-lintas Normal setiap simpang dan Akibat Pembangunan Saluran (APS), seperti disajikan pada Tabel 3 sampai dengan Tabel 5 berikut. 
Tabel 3. Volume Lalu-lintas di Simpang A Tahun 2017

\begin{tabular}{lcccccccc}
\hline \multirow{2}{*}{ Jenis } & \multicolumn{2}{c}{ Utara-Selatan } & \multicolumn{2}{c}{ Selatan-Utara } & \multicolumn{2}{c}{ Barat-Timur } & \multicolumn{2}{c}{ Timur-Barat } \\
& $\begin{array}{c}\text { Normal } \\
\text { kend/jam }\end{array}$ & $\begin{array}{c}\text { APS } \\
\text { kend/jam }\end{array}$ & $\begin{array}{c}\text { Normal } \\
\text { kend/jam }\end{array}$ & $\begin{array}{c}\text { APS } \\
\text { kend/jam }\end{array}$ & $\begin{array}{c}\text { Normal } \\
\text { kend/jam }\end{array}$ & $\begin{array}{c}\text { APS } \\
\text { kend/jam }\end{array}$ & $\begin{array}{c}\text { Normal } \\
\text { kend/jam }\end{array}$ & $\begin{array}{c}\text { APS } \\
\text { kendjam }\end{array}$ \\
\hline Bus/Truk Kecil & 141 & 10 & 62 & 10 & 18 & 17 & 55 & 22 \\
Bus/Truk Besar & 4 & 4 & 38 & 10 & 4 & 4 & 1 & 0 \\
Sepeda Motor & 365 & - & 568 & - & 274 & - & 333 & - \\
\hline
\end{tabular}

Tabel 4. Volume Lalu-lintas di Simpang B Tahun 2017

\begin{tabular}{lcccccccc}
\hline \multicolumn{1}{c}{ Jenis } & \multicolumn{2}{c}{ Utara-Selatan } & \multicolumn{2}{c}{ Selatan-Utara } & \multicolumn{2}{c}{ Barat-Timur } & \multicolumn{2}{c}{ Timur-Barat } \\
& $\begin{array}{c}\text { Normal } \\
\text { kend/jam }\end{array}$ & $\begin{array}{c}\text { APS } \\
\text { kend/jam }\end{array}$ & $\begin{array}{c}\text { Normal } \\
\text { kend/jam }\end{array}$ & $\begin{array}{c}\text { APS } \\
\text { kend/jam }\end{array}$ & $\begin{array}{c}\text { Normal } \\
\text { kend/jam }\end{array}$ & $\begin{array}{c}\text { APS } \\
\text { kend/jam }\end{array}$ & $\begin{array}{c}\text { Normal } \\
\text { kend/jam }\end{array}$ & $\begin{array}{c}\text { APS } \\
\text { kend/jam }\end{array}$ \\
\hline Bus/Truk Kecil & 10 & 7 & 8 & 9 & 15 & 14 & 11 & 10 \\
Bus/Truk Besar & 2 & 1 & 1 & 1 & 2 & 1 & 1 & 2 \\
Sepeda Motor & 242 & - & 300 & - & 554 & - & 344 & - \\
\hline
\end{tabular}

Tabel 5. Volume Lalu-lintas di Simpang C Tahun 2017

\begin{tabular}{lcccccccc}
\hline \multirow{2}{*}{ Jenis } & \multicolumn{2}{c}{ Utara-Selatan } & \multicolumn{2}{c}{ Selatan-Utara } & \multicolumn{2}{c}{ Barat-Timur } & \multicolumn{2}{c}{ Timur-Barat } \\
& $\begin{array}{c}\text { Normal } \\
\text { kend/jam }\end{array}$ & $\begin{array}{c}\text { APS } \\
\text { kend/jam }\end{array}$ & $\begin{array}{c}\text { Normal } \\
\text { kend/jam }\end{array}$ & $\begin{array}{c}\text { APS } \\
\text { kend/jam }\end{array}$ & $\begin{array}{c}\text { Normal } \\
\text { kend/jam }\end{array}$ & $\begin{array}{c}\text { APS } \\
\text { kend/jam }\end{array}$ & $\begin{array}{c}\text { Normal } \\
\text { kend/jam }\end{array}$ & $\begin{array}{c}\text { APS } \\
\text { kend/jam }\end{array}$ \\
\hline Bus/Truk Kecil & 2 & 1 & 4 & 2 & 5 & 4 & 5 & 5 \\
Bus/Truk Besar & 0 & 0 & 1 & 1 & 2 & 1 & 1 & 0 \\
Sepeda Motor & 179 & - & 302 & - & 180 & - & 562 & - \\
\hline
\end{tabular}

\section{ANALISIS DAN PENELITIAN}

Dalam masa konstruksi pembangunan saluran irigasi sekunder, ketiga simpang dilewati oleh kendaraan bus kecil \& truk kecil (LV), bus besar \& truk besar (HV), dan sepeda motor (MC). Kinerja ketiga Simpang di Kedungpring tersebut dilihat berdasarkan parameter Derajat Kejenuhan dan Tundaan Rata-rata. Volume lalu-lintas pada tahun 2018 tidak dicacah lagi, tapi diprediksi berdasarkan volume lalu-lintas tahun 2017 dikalikan dengan faktor pertumbuhan lalu-lintas Kabupaten Lamongan. Sebagai peramalan digunakan data pertumbuhan kendaraan yang tertulis pada Buku Kabupaten Lamongan Dalam Angka Badan Pusat Statistik (BPS) Kabupaten Lamongan seperti tertulis pada Tabel 6

Tabel 6. Pertumbuhan Kendaaraan LV, HV, dan MC, Kabupaten Lamongan.

\begin{tabular}{lcccccc}
\hline Jenis & \multicolumn{5}{c}{ Tahun } & \multicolumn{2}{c}{ Pertumbuhan } \\
Kend & $\mathbf{2 0 1 2}$ & $\mathbf{2 0 1 3}$ & $\mathbf{2 0 1 4}$ & $\mathbf{2 0 1 5}$ & $\mathbf{2 0 1 6}$ & \\
& Kendaraan & Kendaraan & Kendaraan & Kendaraan & Kendaraan & \\
\hline LV & 617 & 933 & 1052 & 1093 & 1184 & $7,6 \%$ \\
HV & 62 & 86 & 87 & 86 & 87 & $1,6 \%$ \\
MC & 31601 & 43223 & 43366 & 47435 & 51202 & $7,1 \%$ \\
\hline
\end{tabular}

Volume lalu-lintas tahun 2017 adalah lalu-lintas Normal ditambah kendaraan berat/barang Akibat Pembangunan Saluran (APS). Volume lalu-lintas tahun 2018 adalah lalulintas Normal ditambah kendaraan berat/barang APS. Sedangkan volume lalu-lintas tahun 2019 yaitu hanya lalu-lintas Normal, karena pembangunan saluran telah selesai.

Angka pertumbuhan kendaraan yang dihitung dan disajikan pada Tabel 4 digunakan untuk menghitung prediksi volume lalu-lintas Normal. Prediksi lalu-lintas ketiga simpang dapat dilihat pada Tabel 7 sampai dengan Tabel 9 berikut ini. 
(e)ISSN 2615-1847 (p)ISSN 2615-1839

Jurnal Manajemen Aset Infrastruktur \& Fasilitas - Vol. 2, No.2, September 2018

Tabel 7. Prediksi Volume Lalu-lintas di Simpang A

\begin{tabular}{|c|c|c|c|c|c|c|c|c|c|c|c|c|}
\hline \multirow[b]{2}{*}{$\begin{array}{l}\text { Tahun/ } \\
\text { Jenis }\end{array}$} & \multicolumn{3}{|c|}{ Utara-Selatan } & \multicolumn{3}{|c|}{ Selatan-Utara } & \multicolumn{3}{|c|}{ Barat-Timur } & \multicolumn{3}{|c|}{ Timur-Barat } \\
\hline & $\begin{array}{c}\text { Normal } \\
\text { kend/ } \\
\text { jam }\end{array}$ & $\begin{array}{c}\text { APS } \\
\text { kend/ } \\
\text { jam }\end{array}$ & $\begin{array}{c}\text { Jumlah } \\
\text { kend } \\
\text { /jam }\end{array}$ & $\begin{array}{c}\text { Normal } \\
\text { kend/ } \\
\text { jam }\end{array}$ & $\begin{array}{c}\text { APS } \\
\text { kend/ } \\
\text { jam }\end{array}$ & $\begin{array}{c}\text { Jumlah } \\
\text { kend/ } \\
\text { jam }\end{array}$ & $\begin{array}{c}\text { Normal } \\
\text { kend/ } \\
\text { jam }\end{array}$ & $\begin{array}{c}\text { APS } \\
\text { kend/ } \\
\text { jam }\end{array}$ & $\begin{array}{c}\text { Jumlah } \\
\text { kend/ } \\
\text { jam }\end{array}$ & $\begin{array}{c}\text { Normal } \\
\text { kend/ } \\
\text { jam }\end{array}$ & $\begin{array}{l}\text { APS } \\
\text { kend/ } \\
\text { jam }\end{array}$ & $\begin{array}{c}\text { Jumlah } \\
\text { kend/ } \\
\text { jam }\end{array}$ \\
\hline $\begin{array}{c}2017 \\
\mathrm{HV}+\mathrm{LV}\end{array}$ & 145 & 14 & 159 & 100 & 20 & 120 & 21 & 21 & 42 & 56 & 20 & 76 \\
\hline $\mathrm{MC}$ & 365 & - & 365 & 568 & - & 568 & 274 & - & 274 & 333 & - & 333 \\
\hline $\begin{array}{c}2018 \\
H V+L V\end{array}$ & 156 & 14 & 170 & 105 & 20 & 125 & 23 & 21 & 44 & 61 & 20 & 81 \\
\hline $\mathrm{MC}$ & 391 & - & 391 & 608 & - & 608 & 293 & - & 293 & 357 & - & 357 \\
\hline $\begin{array}{c}2019 \\
\mathrm{HV}+\mathrm{LV}\end{array}$ & 167 & - & 167 & 111 & - & 111 & 24 & - & 24 & 63 & - & 63 \\
\hline MC & 419 & - & 419 & 652 & - & 652 & 314 & - & 314 & 382 & - & 382 \\
\hline
\end{tabular}

Tabel 8. Prediksi Volume Lalu-lintas di Simpang B

\begin{tabular}{|c|c|c|c|c|c|c|c|c|c|c|c|c|}
\hline \multirow{2}{*}{$\begin{array}{l}\text { Tahun/ } \\
\text { Jenis }\end{array}$} & \multicolumn{3}{|c|}{ Utara-Selatan } & \multicolumn{3}{|c|}{ Selatan-Utara } & \multicolumn{3}{|c|}{ Barat-Timur } & \multicolumn{3}{|c|}{ Timur-Barat } \\
\hline & $\begin{array}{c}\text { Normal } \\
\text { kend/ } \\
\text { jam }\end{array}$ & $\begin{array}{c}\text { APS } \\
\text { kend/ } \\
\text { jam }\end{array}$ & $\begin{array}{c}\text { Jumlah } \\
\text { kend } \\
\text { /jam }\end{array}$ & $\begin{array}{c}\text { Normal } \\
\text { kend/ } \\
\text { jam }\end{array}$ & $\begin{array}{c}\text { APS } \\
\text { kend/ } \\
\text { jam }\end{array}$ & $\begin{array}{c}\text { Jumlah } \\
\text { kend/ } \\
\text { jam }\end{array}$ & $\begin{array}{c}\text { Normal } \\
\text { kend/ } \\
\text { jam }\end{array}$ & $\begin{array}{c}\text { APS } \\
\text { kend/ } \\
\text { jam }\end{array}$ & $\begin{array}{c}\text { Jumlah } \\
\text { kend/ } \\
\text { jam }\end{array}$ & $\begin{array}{c}\text { Normal } \\
\text { kend/ } \\
\text { jam }\end{array}$ & $\begin{array}{c}\text { APS } \\
\text { kend/ } \\
\text { jam }\end{array}$ & $\begin{array}{c}\text { Jumlah } \\
\text { kend/ } \\
\text { jam }\end{array}$ \\
\hline $\begin{array}{c}2017 \\
\mathrm{HV}+\mathrm{LV}\end{array}$ & 6 & 11 & 17 & 12 & 9 & 21 & 16 & 15 & 31 & 10 & 11 & 21 \\
\hline $\mathrm{MC}$ & 242 & - & 242 & 300 & - & 300 & 554 & - & 554 & 344 & - & 344 \\
\hline $\begin{array}{c}2018 \\
\mathrm{HV}+\mathrm{LV}\end{array}$ & 7 & 11 & 18 & 14 & 9 & 23 & 17 & 15 & 32 & 12 & 11 & 23 \\
\hline $\mathrm{MC}$ & 259 & - & 259 & 321 & - & 321 & 593 & - & 593 & 368 & - & 368 \\
\hline $\begin{array}{c}2019 \\
\mathrm{HV}+\mathrm{LV}\end{array}$ & 10 & - & 10 & 12 & - & 12 & 18 & - & 18 & 12 & - & 12 \\
\hline $\mathrm{MC}$ & 277 & - & 277 & 344 & - & 344 & 635 & - & 635 & 395 & - & 395 \\
\hline
\end{tabular}

Tabel 9. Prediksi Volume Lalu-lintas di Simpang C

\begin{tabular}{|c|c|c|c|c|c|c|c|c|c|c|c|c|}
\hline \multirow{2}{*}{$\begin{array}{l}\text { Tahun/ } \\
\text { Jenis }\end{array}$} & \multicolumn{3}{|c|}{ Utara-Selatan } & \multicolumn{3}{|c|}{ Selatan-Utara } & \multicolumn{3}{|c|}{ Barat-Timur } & \multicolumn{3}{|c|}{ Timur-Barat } \\
\hline & $\begin{array}{c}\text { Normal } \\
\text { kend/ } \\
\text { jam }\end{array}$ & $\begin{array}{c}\text { APS } \\
\text { kend/ } \\
\text { jam }\end{array}$ & $\begin{array}{c}\text { Jumlah } \\
\text { kend } \\
\text { /jam }\end{array}$ & $\begin{array}{c}\text { Normal } \\
\text { kend/ } \\
\text { jam }\end{array}$ & $\begin{array}{c}\text { APS } \\
\text { kend/ } \\
\text { jam }\end{array}$ & $\begin{array}{c}\text { Jumlah } \\
\text { kend/ } \\
\text { jam }\end{array}$ & $\begin{array}{c}\text { Normal } \\
\text { kend/ } \\
\text { jam }\end{array}$ & $\begin{array}{c}\text { APS } \\
\text { kend/ } \\
\text { jam }\end{array}$ & $\begin{array}{c}\text { Jumlah } \\
\text { kend/ } \\
\text { jam }\end{array}$ & $\begin{array}{c}\text { Normal } \\
\text { kend/ } \\
\text { jam }\end{array}$ & $\begin{array}{c}\text { APS } \\
\text { kend/ } \\
\text { jam }\end{array}$ & $\begin{array}{c}\text { Jumlah } \\
\text { kend/ } \\
\text { jam }\end{array}$ \\
\hline $\begin{array}{c}2017 \\
\text { HV+LV }\end{array}$ & 1 & 2 & 3 & 1 & 5 & 6 & 6 & 5 & 11 & 5 & 6 & 11 \\
\hline $\mathrm{MC}$ & 179 & - & 179 & 302 & - & 302 & 180 & - & 180 & 562 & - & 562 \\
\hline $\begin{array}{c}2018 \\
\mathrm{HV}+\mathrm{LV}\end{array}$ & 1 & 2 & 3 & 3 & 5 & 8 & 6 & 5 & 11 & 5 & 6 & 11 \\
\hline $\mathrm{MC}$ & 192 & - & 192 & 324 & - & 324 & 193 & - & 193 & 602 & - & 602 \\
\hline $\begin{array}{c}2019 \\
\mathrm{HV}+\mathrm{LV}\end{array}$ & 1 & - & 1 & 3 & - & 3 & 7 & - & 7 & 6 & - & 6 \\
\hline $\mathrm{MC}$ & 205 & - & 205 & 347 & - & 347 & 206 & - & 206 & 645 & - & 645 \\
\hline
\end{tabular}

Arus lalu-lintas berdasarkan jenis kendaraan, dihitung dalam satuan smp (Satuan Mobil Penumpang) di Simpang A Jalan Raya Babat - Jalan Kalen, disampaikan pada Tabel 10 berikut ini. 
Tabel 10. Volume Lalu-lintas di Simpang A Berdasarkan Jenis Kendaraan dalam Nilai smp

\begin{tabular}{|c|c|c|c|c|c|c|c|c|c|}
\hline \multirow{2}{*}{$\begin{array}{c}\text { Tahun/ } \\
\text { Jenis }\end{array}$} & \multicolumn{2}{|c|}{ Utara-Selatan } & \multicolumn{2}{|c|}{ Selatan-Utara } & \multicolumn{2}{|c|}{ Barat-Timur } & \multicolumn{2}{|c|}{ Timur-Barat } & \multirow{2}{*}{$\begin{array}{c}\text { Jumlah } \\
\text { smp/ } \\
\text { jam }\end{array}$} \\
\hline & $\begin{array}{c}\text { Normal } \\
\text { smp/ } \\
\text { jam }\end{array}$ & $\begin{array}{l}\text { APS } \\
\text { smp/ } \\
\text { jam }\end{array}$ & $\begin{array}{c}\text { Normal } \\
\text { smp/ } \\
\text { jam }\end{array}$ & $\begin{array}{l}\text { APS } \\
\text { smp/ } \\
\text { jam }\end{array}$ & $\begin{array}{c}\text { Normal } \\
\text { smp/ } \\
\text { jam }\end{array}$ & $\begin{array}{l}\text { APS } \\
\text { smp/ } \\
\text { jam }\end{array}$ & $\begin{array}{c}\text { Normal } \\
\text { smp/ } \\
\text { jam }\end{array}$ & $\begin{array}{l}\text { APS } \\
\text { smp/ } \\
\text { jam }\end{array}$ & \\
\hline $\begin{array}{c}2017 \\
H V+L V\end{array}$ & 146 & 15 & 112 & 21 & 22 & 22 & 54 & 22 & 1185 \\
\hline $\mathrm{MC}$ & 183 & - & 284 & - & 137 & - & 167 & - & \\
\hline $\begin{array}{c}2018 \\
H V+L V\end{array}$ & 157 & 15 & 119 & 21 & 25 & 22 & 59 & 22 & 1265 \\
\hline $\mathrm{MC}$ & 195 & - & 304 & - & 147 & - & 178 & - & \\
\hline $\begin{array}{c}2019 \\
H V+L V\end{array}$ & 169 & - & 123 & - & 26 & - & 63 & - & 1137 \\
\hline $\mathrm{MC}$ & 209 & - & 326 & - & 157 & - & 191 & - & \\
\hline
\end{tabular}

Hasil perhitungan kinerja Simpang A Jalan Raya Babat - Jalan Kalen dihitung berdasarkan DK Pada tahun 2017 ke tahun 2018 nilai DK meningkat diakibatkan pertumbuhan arus lalu-lintas kendaraan normal ditambah dengan kendaraan akibat pembangunan saluran. Sedangkan tahun 2019 nilai DK turun karena masa pembangunan saluran telah selesai. Untuk lebih jelasnya kinerja Simpang A Jalan Raya Babat - Jalan Kalen disampaikan pada Tabel 11 berikut ini.

Tabel 11. Simpang A Jalan Raya Babat - Jalan Kalen Tahun 2017, 2018, dan 2019

\begin{tabular}{cccc}
\hline Tahun & $\begin{array}{c}\text { Arus Lalu-lintas (LL) } \\
\text { smp/jam }\end{array}$ & $\begin{array}{c}\text { Kapasitas (K) } \\
\text { smp/jam }\end{array}$ & DK \\
\hline 2017 & 1185 & 1816,108 & 0,653 \\
2018 & 1265 & 1816,108 & 0,696 \\
2019 & 1137 & 1816,108 & 0,626 \\
\hline
\end{tabular}

Kinerja Simpang A Jalan Raya Babat - Jalan Kalen untuk Tahun 2019 menghasilkan DK 0,626 dan TR sebesar $28 \mathrm{det} / \mathrm{smp}$. Hal ini disebabkan pertumbuhan mobil barang arus lalu-lintas normal turut membebani simpang Jalan Kalen yang datang dari arah Jalan Raya Babat. Untuk lebih jelasnya kinerja Simpang A Jalan Raya Babat - Jalan Kalen untuk Tahun 2019 disampaikan pada Gambar 3 berikut ini. 


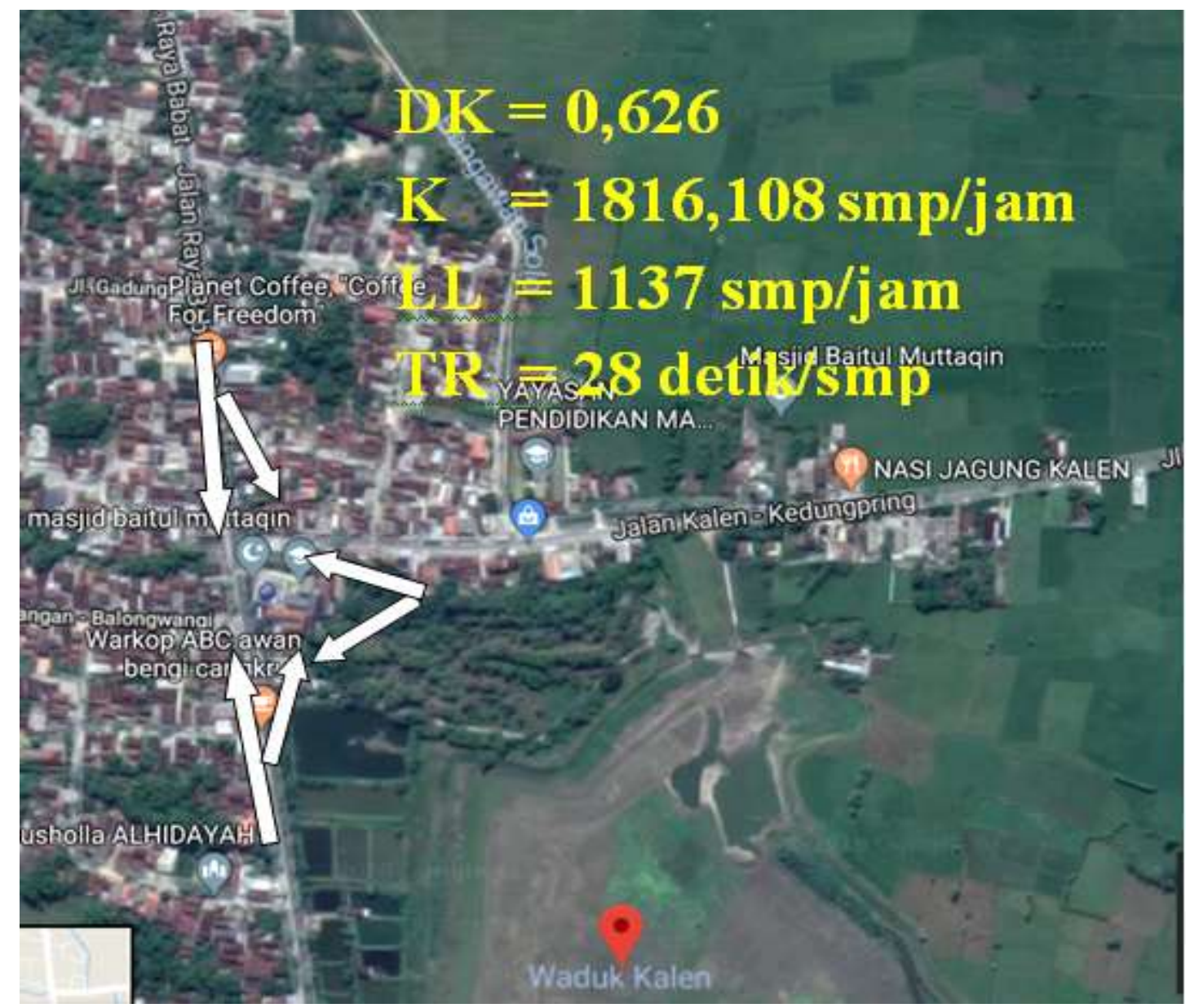

Gambar 3. Kinerja Simpang A Jalan Raya Babat - Jalan Kalen Tahun 2019

Arus lalu-lintas berdasarkan jenis kendaraan, dihitung dalam satuan smp (Satuan Mobil Penumpang) di Simpang B Jalan Kalen - Jalan Kedungpring, disampaikan pada Tabel 12 berikut ini.

Tabel 12. Volume Lalu-lintas di Simpang B Berdasarkan Jenis Kendaraan dalam Nilai smp

\begin{tabular}{|c|c|c|c|c|c|c|c|c|c|}
\hline \multirow{2}{*}{$\begin{array}{l}\text { Tahun/ } \\
\text { Jenis }\end{array}$} & \multicolumn{2}{|c|}{ Utara-Selatan } & \multicolumn{2}{|c|}{ Selatan-Utara } & \multicolumn{2}{|c|}{ Barat-Timur } & \multicolumn{2}{|c|}{ Timur-Barat } & \multirow[b]{2}{*}{$\begin{array}{c}\text { Jumlah } \\
\text { smp/ } \\
\text { jam }\end{array}$} \\
\hline & $\begin{array}{c}\text { Normal } \\
\text { smp/ } \\
\text { jam }\end{array}$ & $\begin{array}{l}\text { APS } \\
\text { smp/ } \\
\text { jam }\end{array}$ & $\begin{array}{c}\text { Normal } \\
\text { smp/ } \\
\text { jam }\end{array}$ & $\begin{array}{l}\text { APS } \\
\text { smp/ } \\
\text { jam }\end{array}$ & $\begin{array}{c}\text { Normal } \\
\text { smp/ } \\
\text { jam }\end{array}$ & $\begin{array}{l}\text { APS } \\
\text { smp/ } \\
\text { jam }\end{array}$ & $\begin{array}{c}\text { Normal } \\
\text { smp/ } \\
\text { jam }\end{array}$ & $\begin{array}{l}\text { APS } \\
\text { smp/ } \\
\text { jam }\end{array}$ & \\
\hline $\begin{array}{c}2017 \\
\mathrm{HV}+\mathrm{LV}\end{array}$ & 6 & 11 & 12 & 10 & 16 & 16 & 9 & 12 & 812 \\
\hline $\mathrm{MC}$ & 150 & - & 121 & - & 277 & - & 172 & - & \\
\hline $\begin{array}{c}2018 \\
H V+L V\end{array}$ & 8 & 11 & 14 & 10 & 17 & 16 & 11 & 12 & 870 \\
\hline $\mathrm{MC}$ & 160 & - & 130 & - & 297 & - & 184 & - & \\
\hline $\begin{array}{c}2019 \\
H V+L V\end{array}$ & 10 & - & 12 & - & 19 & - & 12 & - & 879 \\
\hline $\mathrm{MC}$ & 172 & - & 151 & - & 318 & - & 197 & - & \\
\hline
\end{tabular}

Hasil perhitungan kinerja Simpang B Jalan Kalen - Jalan Kedungpring dihitung berdasarkan DK. Pada tahun 2017 ke tahun 2018 nilai DK meningkat diakibatkan pertumbuhan arus lalu-lintas kendaraan normal ditambah dengan kendaraan akibat pembangunan saluran. Sedangkan tahun 2019 nilai DK juga meningkat karena kehilangan 
arus lalu-lintas APS lebih kecil dari pertumbuhan kendaraan. Untuk lebih jelasnya kinerja Simpang B Jalan Kalen - Jalan Kedungpring disampaikan pada Tabel 13 berikut ini.

Tabel 13. Simpang B Jalan Kalen - Jalan Kedungpring Tahun 2017, 2018, dan 2019

\begin{tabular}{cccc}
\hline Tahun & $\begin{array}{c}\text { Arus Lalu-lintas (LL) } \\
\text { smp/jam }\end{array}$ & $\begin{array}{c}\text { Kapasitas (K) } \\
\text { smp/jam }\end{array}$ & DK \\
\hline 2017 & 812 & 1361,160 & 0,596 \\
2018 & 870 & 1361,160 & 0,639 \\
2019 & 879 & 1361,160 & 0,646 \\
\hline
\end{tabular}

Kinerja Simpang B Jalan Kalen - Jalan Kedungpring untuk Tahun 2019 menghasilkan DK 0,646 dan TR sebesar $35 \mathrm{det} / \mathrm{smp}$. Hal ini disebabkan pertumbuhan mobil barang arus lalu-lintas normal turut membebani simpang Jalan Kedungpring yang datang dari arah Jalan Kalen. Untuk lebih jelasnya kinerja Simpang B Jalan Kalen - Jalan Kedungpring untuk Tahun 2019 disampaikan pada Gambar 4 berikut ini.

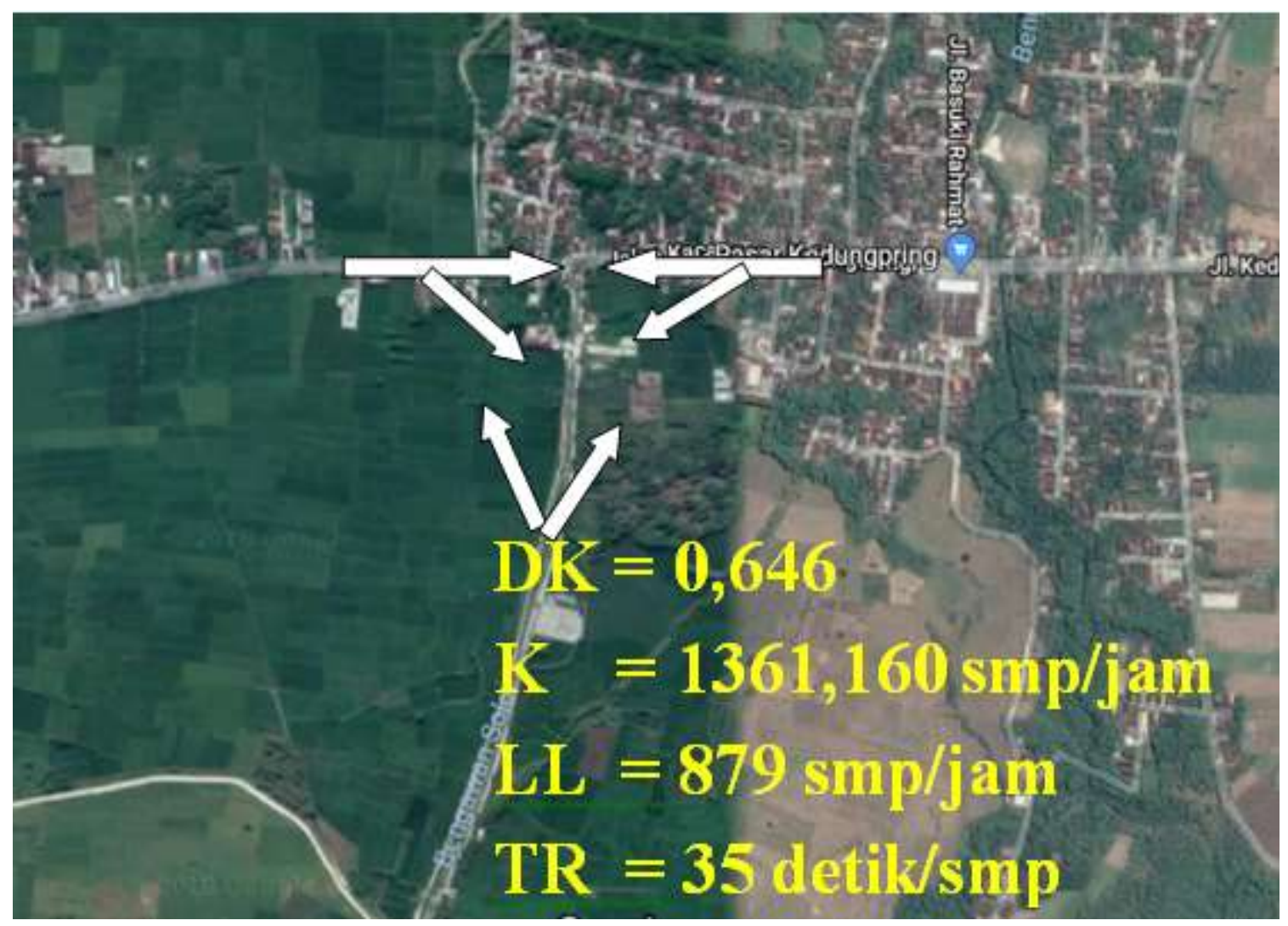

Gambar 4. Kinerja Simpang B Jalan Kalen - Jalan Kedungpring Tahun 2019

Arus lalu-lintas berdasarkan jenis kendaraan, dihitung dalam satuan smp (Satuan Mobil Penumpang) di Simpang C Jalan Kedungpring - Jalan Majenang, disampaikan pada Tabel 14 berikut ini. 
Tabel 14. Volume Lalu-lintas di Simpang C Berdasarkan Jenis Kendaraan dalam Nilai smp

\begin{tabular}{|c|c|c|c|c|c|c|c|c|c|}
\hline \multirow{2}{*}{$\begin{array}{l}\text { Tahun/ } \\
\text { Jenis }\end{array}$} & \multicolumn{2}{|c|}{ Utara-Selatan } & \multicolumn{2}{|c|}{ Selatan-Utara } & \multicolumn{2}{|c|}{ Barat-Timur } & \multicolumn{2}{|c|}{ Timur-Barat } & \multirow[b]{2}{*}{$\begin{array}{c}\text { Jumlah } \\
\text { smp/ } \\
\text { jam }\end{array}$} \\
\hline & $\begin{array}{c}\text { Normal } \\
\text { smp/ } \\
\text { jam }\end{array}$ & $\begin{array}{l}\text { APS } \\
\text { smp/ } \\
\text { jam }\end{array}$ & $\begin{array}{c}\text { Normal } \\
\text { smp/ } \\
\text { jam }\end{array}$ & $\begin{array}{l}\text { APS } \\
\text { smp/ } \\
\text { jam }\end{array}$ & $\begin{array}{c}\text { Normal } \\
\text { smp/ } \\
\text { jam }\end{array}$ & $\begin{array}{c}\text { APS } \\
\text { smp/ } \\
\text { jam }\end{array}$ & $\begin{array}{c}\text { Normal } \\
\text { smp/ } \\
\text { jam }\end{array}$ & $\begin{array}{l}\text { APS } \\
\text { smp/ } \\
\text { jam }\end{array}$ & \\
\hline $\begin{array}{c}2017 \\
H V+L V\end{array}$ & 1 & 2 & 1 & 5 & 6 & 5 & 5 & 6 & 641 \\
\hline $\mathrm{MC}$ & 151 & - & 90 & - & 90 & - & 281 & - & \\
\hline $\begin{array}{c}2018 \\
H V+L V\end{array}$ & 1 & 2 & 4 & 5 & 7 & 5 & 6 & 6 & 691 \\
\hline $\mathrm{MC}$ & 161 & - & 96 & - & 96 & - & 301 & - & \\
\hline $\begin{array}{c}2019 \\
H V+L V\end{array}$ & 1 & - & 4 & - & 7 & - & 6 & - & 718 \\
\hline $\mathrm{MC}$ & 173 & - & 102 & - & 103 & - & 322 & - & \\
\hline
\end{tabular}

Hasil perhitungan kinerja Simpang C Jalan Kedungpring - Jalan Majenang dihitung berdasarkan DK. Pada tahun 2017 ke tahun 2018 nilai DK meningkat diakibatkan pertumbuhan arus lalu-lintas kendaraan normal ditambah dengan kendaraan akibat pembangunan saluran. Sedangkan tahun 2019 nilai DK juga meningkat karena kehilangan arus lalu-lintas APS lebih kecil dari pertumbuhan kendaraan. Untuk lebih jelasnya kinerja Simpang C Jalan Kedungpring - Jalan Majenang disampaikan pada Tabel 15 berikut ini.

Tabel 15. Simpang C Jalan Kedungpring - Jalan Majenang Tahun 2017, 2018, dan 2019

\begin{tabular}{cccc}
\hline Tahun & $\begin{array}{c}\text { Arus lalu-lintas (LL) } \\
\text { smp/jam }\end{array}$ & $\begin{array}{c}\text { Kapasitas (K) } \\
\text { smp/jam }\end{array}$ & DK \\
\hline 2017 & 641 & 1842,042 & 0,348 \\
2018 & 691 & 1842,042 & 0,375 \\
2019 & 718 & 1842,042 & 0,390 \\
\hline
\end{tabular}

Kinerja Simpang C Jalan Kedungpring - Jalan Majenang untuk Tahun 2019 menghasilkan DK 0,390 dan TR sebesar 39 det/smp. Hal ini disebabkan pertumbuhan mobil barang arus lalu-lintas normal turut membebani simpang Jalan Majenang yang datang dari arah Jalan Kedungpring. Untuk lebih jelasnya kinerja Simpang C Jalan Kedungpring - Jalan Majenang untuk Tahun 2019 disampaikan pada Gambar 5 berikut ini. 


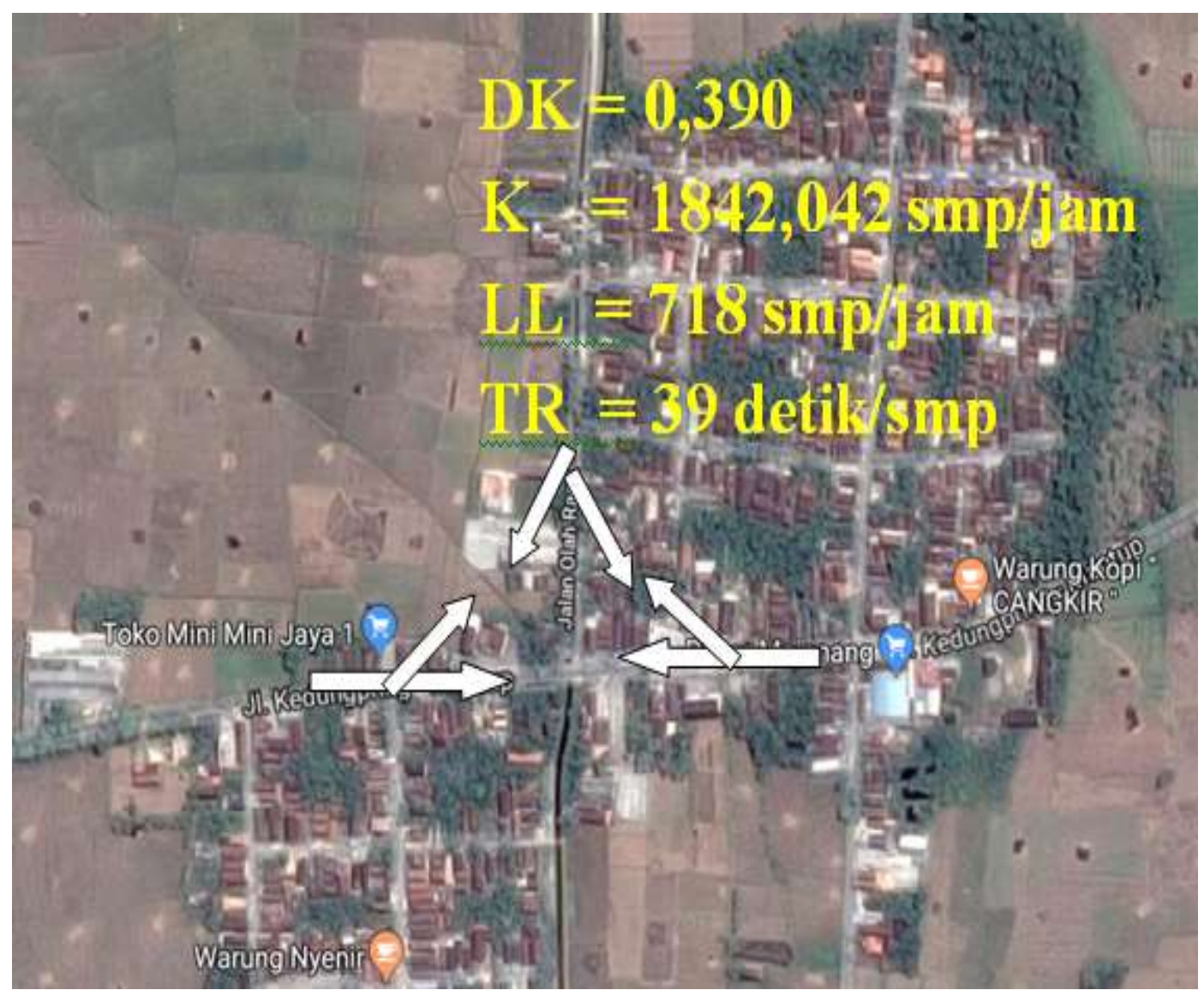

Gambar 5. Kinerja Simpang C Jalan Kedungpring - Jalan Majenang Tahun 2019

Tahun 2017 ke tahun 2018 nilai DK ketiga simpang meningkat diakibatkan pertumbuhan arus lalu-lintas kendaraan normal ditambah dengan kendaraan akibat pembangunan saluran. Tahun 2019 untuk Simpang A nilai DK turun karena masa pembangunan saluran telah selesai, sedangkan untuk Simpang B dan C nilai DK meningkat karena kehilangan arus lalu-lintas APS lebih kecil dari pertumbuhan kendaraan. Untuk lebih jelasnya perbandingan kinerja lalu-lintas tiap simpang disampaikan pada Tabel 16 berikut.

Tabel 16. Perbandingan Kinerja Lalu-lintas Simpang Kedungpring

\begin{tabular}{|c|c|c|c|c|c|c|}
\hline \multirow{2}{*}{$\begin{array}{c}\text { Tahun } \\
\text { SIMPANG }\end{array}$} & \multicolumn{2}{|c|}{$\begin{array}{c}2017 \\
\text { (Survei) }\end{array}$} & \multicolumn{2}{|c|}{$\begin{array}{c}2018 \\
\text { (Masa Konstruksi) }\end{array}$} & \multicolumn{2}{|c|}{$\begin{array}{c}2019 \\
\text { (Pasca Konstruksi) }\end{array}$} \\
\hline & DK & $\begin{array}{c}\mathbf{T R} \\
\text { detik/smp }\end{array}$ & DK & $\begin{array}{c}\mathbf{T R} \\
\mathrm{detik} / \mathrm{smp}\end{array}$ & DK & $\begin{array}{c}\mathbf{T R} \\
\mathrm{detik} / \mathrm{smp}\end{array}$ \\
\hline \multirow[b]{2}{*}{$\begin{array}{l}\text { SIMPANG } \\
\text { A }\end{array}$} & 0,653 & & 0,696 & & 0,626 & \\
\hline & $\begin{array}{l}\text { TP C } \\
\text { (cukup) }\end{array}$ & 30,432 & $\begin{array}{l}\text { TP C } \\
\text { (cukup) }\end{array}$ & 32,250 & $\begin{array}{l}\text { TP C } \\
\text { (cukup) }\end{array}$ & 28,488 \\
\hline \multirow[b]{2}{*}{$\begin{array}{c}\text { SIMPANG } \\
\text { B }\end{array}$} & 0,596 & & 0,639 & & 0,646 & \\
\hline & $\begin{array}{l}\text { TP C } \\
\text { (cukup) }\end{array}$ & 30,825 & $\begin{array}{l}\text { TP C } \\
\text { (cukup) }\end{array}$ & 33,054 & $\begin{array}{l}\text { TP C } \\
\text { (cukup) }\end{array}$ & 35,436 \\
\hline \multirow[b]{2}{*}{$\begin{array}{l}\text { SIMPANG } \\
\text { C }\end{array}$} & 0,348 & & 0,375 & & 0,390 & \\
\hline & $\begin{array}{l}\text { TP B } \\
\text { (baik) }\end{array}$ & 34,690 & $\begin{array}{l}\text { TP B } \\
\text { (baik) }\end{array}$ & 36,748 & $\begin{array}{l}\text { TP B } \\
\text { (baik) }\end{array}$ & 39,270 \\
\hline
\end{tabular}




\section{KESIMPULAN}

Hasil perhitungan kinerja lalu-lintas ketiga simpang di Kedungpring menunjukkan Derajat Kejenuhan (DK), dan Tingkat Pelayanan (TP) tiap simpang sebagai berikut:

- Tahun 2017 ke Tahun 2018 nilai DK ketiga simpang meningkat diakibatkan pertumbuhan arus lalu-lintas kendaraan normal ditambah dengan kendaraan akibat pembangunan saluran. Tahun 2019 untuk Simpang A nilai DK turun karena masa pembangunan saluran telah selesai. Sedangkan untuk Simpang B dan C nilai DK meningkat karena kehilangan arus lalu-lintas APS lebih kecil dari pertumbuhan kendaraan.

- Kinerja lalu-lintas untuk simpang A pada tahun 2017 adalah $\mathrm{DK}=0,653$ dan $\mathrm{TP}=\mathrm{C}$ (Cukup), pada tahun 2018 adalah $\mathrm{DK}=0,696$ dan $\mathrm{TP}=\mathrm{C}$ (Cukup), sedangkan pada tahun 2019 adalah $\mathrm{DK}=0,626$ dan $\mathrm{TP}=\mathrm{C}$ (Cukup).

- Kinerja lalu-lintas untuk simpang B pada tahun 2017 adalah $\mathrm{DK}=0,596$ dan $\mathrm{TP}=\mathrm{C}$ (Cukup), pada tahun 2018 adalah $\mathrm{DK}=0,639$ dan $\mathrm{TP}=\mathrm{C}$ (Cukup), sedangkan pada tahun 2019 adalah $\mathrm{DK}=0,646$ dan $\mathrm{TP}=\mathrm{C}$ (Cukup).

- Kinerja lalu-lintas untuk simpang $\mathrm{C}$ pada tahun 2017 adalah $\mathrm{DK}=0,348$ dan $\mathrm{TP}=\mathrm{B}$ (Baik), pada tahun 2018 adalah $\mathrm{DK}=0,375$ dan $\mathrm{TP}=\mathrm{B}$ (Baik), sedangkan pada tahun 2019 adalah $\mathrm{DK}=0,390$ dan $\mathrm{TP}=\mathrm{C}$ (Cukup).

Analisis kinerja lalu-lintas di Kecamatan Kedungpring Kabupaten Lamongan yang diuraikan diatas, memicu pengembangan penelitian lanjutan sebagai berikut:

- Analisis Variasi Biaya Operasional Kendaraan (BOK) Akibat Pembangunan Saluran Irigasi Waduk Kalen pada Simpang Kalen-Majenang di Kecamatan Kedungpring, Lamongan.

- Analisis Metode Prediksi Pertumbuhan Jumlah Kendaraan di Kota Surabaya.

- Tinjauan Kinerja Lalu-lintas Simpang Klampis Jaya - Arif Rachman Hakim di Kota Surabaya.

\section{DAFTAR PUSTAKA}

Badan Pusat Statistik (2015). Kabupaten Lamongan Dalam Angka. Badan Pusat Statistik Kabupaten Lamongan. Lamongan.

MKJI (1997). Manual Kapasitas Jalan Indonesia. Bina Karya \& Sweeroad. Direktorat Bina Jalan Kota. Direktorat Jendral Bina Marga. Jakarta.

McShane, William R. \& Roess, Roger P. (1990). Traffic Engineering. Pearson Higher Education, Inc. New Jersey.

Miro, Fidel (2004). Perencanaan Transportasi Untuk Perencana dan Praktisi. Erlangga. Jakarta.

Suprayitno, H. \& Soemitro, R.A.A. (2018). "Preliminary Reflexion on Basic Principle of Infrastructure Asset Management". Jurnal Manajemen Aset Infrastruktur \& Fasilitas, Vol.2, No.1, Maret 2018, hal : 1-10.

Taylor, M.A.P., Young, W. \& Bonsall, P.W. (2000). Understanding Traffic System: Data, Analysis and Presentation. Second Edition. Athenaeum Press Ltd. Gateshead, Tyne and Wear. England. 